\title{
LEARNERS' PERCEPTIONS OF NONVERBAL COMMUNICATION OF ESL TEACHERS
}

\author{
Tahira Asgher $^{1^{*}}$, Aisha Ilyas ${ }^{2}$, Iram Rubab ${ }^{3}$ \\ ${ }^{1 *}$ Assistant Professor, Department of English Linguistics, The Islamia University of Bahawalpur, Pakistan; ${ }^{2}$ Associate \\ Lecturer, Department of English Linguistics, The Islamia University of Bahawalpur, Pakistan; ${ }^{3}$ Assistant Professor, \\ Department of English, GC Women University, Sialkot, Pakistan. \\ Email: ${ }^{1 *}$ tahira.asgher@iub.edu.pk, ${ }^{2}$ aisha.ilyas@iub.edu.pk, ${ }^{3}$ iram.rubab@gcwus.edu.pk
}

Article History: Received on $22^{\text {nd }}$ May 2021, Revised on $30^{\text {th }}$ May 2021, Published on $5^{\text {th }}$ June 2021

\begin{abstract}
Purpose of the Study: The purpose of this research is to investigate the perceptions of the learners about the use of the nonverbal language of teachers in an ESL class. This study aims to highlight the role played by non-verbal language in the class by raising awareness about the importance of gestures, physical appearance, and paralinguistic features of the English teachers.
\end{abstract}

Methodology: This research employs a mixed methodology. A questionnaire, consisting of 37 close-ended questions is used to record the views of the learners about the use of the non-verbal language of their English teachers. Moreover, qualitative interviews are conducted to find out the learners' opinion and their awareness concerning the use of non-verbal language by their English teachers.

Main Findings: The findings indicate that learners hold a positive attitude towards the teachers who use NVL more frequently. Respondents say that they feel more motivated and interested in the class when the teacher looks at us more frequently and move in the class. According to Neuro-linguists, learning of the language can be enhanced by a drastic level if the teacher can grasp the visual attention of the students while oral communication. Therefore, it is to conclude that learners consider the non-verbal language along with paralinguistic features, extremely constructive in the ESL classroom. They find it encouraging and it aids them in comprehending the content.

Application of this Study: The current research will help the practicing language teachers to upgrade their oral communication skills by incorporating the nonverbal cues productively in their classrooms. Furthermore, teacher trainers can make their trainees aware of the importance of the nonverbal part of communication in the ESL classroom either informal lectures or pragmatic preparation.

Novelty/ Originality of this study: This study is unique in the sense that it focuses on the role played by the Non-verbal language particularly in the class where English is taught as a second language. It unveils how the integration of nonverbal language along with oral communication can make English language classroom more industrious and productive.

Keywords: Non-verbal Language, Non-verbal Communication, Paralinguistic Features, Gestures, ESL Classrooms, Pragmatic Preparing,

\section{INTRODUCTION}

Communication is central to human life because all the contact of humans is based on it (Bunglowala \& Bunglowala, 2015). Therefore, effective communication plays a very important role in today's world. O' Connor \& Shumate (2018) states that communicative process can be taken as a multi-dimensional act, where not only the message is conveyed but there are other aspects which are focused too e.g. what kind of emotions or feelings are generated by the message, in what manner the message is conveyed and what is the effect of the message on the receiver. Moreover, effective communication can be used as a tool for motivating people, resolving issues, and conveying ideas at their best.

In second language classrooms, good communication plays a pivotal role (Dockrell et all., 2012). Thus, teachers are required to make their communication constructive to decrease the language learning barriers, lessen the level of language learning anxiety and upsurge the level of language achievement by encouraging students and developing a good rapport with them. In a language class, efficacious communication is the vital component that determines effective teaching. Communication stimulates effective and cognitive learning of the students in the language class. The process of communication transpires in many various means and spoken language is one of the most important modes of course. This kind of communication is identified as verbal communication, in which language is used to covey the meanings. Most people are uninformed of the other kind of communicative procedure that is non-verbal communication (Duke, 1974). Non-verbal communication is an imperative component of the language classroom (Smith, 1979). In our everyday life, maximum communication is oral and $90 \%$ of oral communication rely on non-verbal cues (Andersen, 1998; Knapp \& Hall, 2009). It is supposed that verbal messages hang heavily on the non-verbal cues for productive communication and if there is a conflict between verbal and 
non-verbal message, non-verbal conquests nearly every time. According to Mehrabian, "Communication is 55\% visual, 38\% tonal and $7 \%$ the words we say".

NVC has been ignored especially in the field of language teaching before the mid-70s and 80s. According to Butt (2011), Non-verbal communication can be defined as 'the type of communication without using verbal language or it can be termed as the communication which occurs by sending or receiving wordless cues. Every sort of communication which takes place without using verbal language falls under the category of NVC (Vrij et al., 2019).

In the case of ESL classes, non-verbal communication is an essential part of teaching-learning processes. In the language class, the teacher accomplishes countless activities besides formal teachings, such as motivating and encouraging the students, decreasing the language learning anxiety of students, stimulating or evolving the concepts and all of these tasks require outstanding communication skills on the part of the teacher. Galloway (1968), as cited in Woolfolk and Brooks (1985), observed that "when students listen, they hear words and they observe the behaviour and expressions of the teacher to obtain further information [...]. In the language classroom, NVC can signify the teacher's directions and intentions more accurately and efficiently. It can further help in simplifying the message therefore it augments the effectiveness of English language teaching. Moreover, in an ESL class language anxiety can affect the learners' achievement so NVC can be used effectively in the ESL class to diminish language learning anxiety among the learners and to upsurge the level of achievement of the English language (Butt, 2011). Furthermore, an ESL classroom is student centred and activity-based, where creative thinking, positive attitude, motivation, and attention of students hold a significant role. Language teachers can incorporate non-verbal language into these activities to achieve a class that is more conducive to learning. Moreover, nonverbal signals should be effectually utilized in the ESL class to boost language learning, building rapport, developing healthy relationships with students, to bring them to the 'zone of congruence' (Kesevan, Madzlan, \& Hashim, 2020).

In the language teaching scenario of Pakistan, less importance is given to the non-verbal aspect of communication. Hence, this study throws light on the certain features of the non-verbal communication that accompanies the verbal language to make the learning of language more fruitful and effective. Following are the research questions:

RQ1: What are the perceptions of the learners about the non-verbal communication of their English teacher?

RQ2: What is the role played by non-verbal language in an ESL class?

RQ3: How do students react towards the non-verbal cues of the teacher in ESL classrooms regarding the effectiveness of the approach?

\section{LITERATURE REVIEW}

Right from human evolution, there was a necessity to share feelings, emotions, ideas, and information. People used to communicate to convey their thoughts or emotions even before the language was invented. The early communication was comprised of some simplest signals like blinking or the complex ones like the movement of the whole body (Postman, 2006). After the invention of language, it became the foremost mean of communication. Though people started to make use of verbal language still those signals or movements were integrated into human communication because humans are intrinsically programmed to use and respond to nonverbal cues (Burgoon, Guerrero\& Floyd, 2016). These signals and body movements are termed as the non-verbal part of the language (Pennycook, 1985). The Nonverbal Dictionary of Gestures, Signs and Body Language (Givens, 2002) defines NVC as, "The process of sending and receiving wordless messages using facial expressions, gaze, gesture, posture, and tone of voice. Also encompassed body positioning in space and grooming habits [...]. An NV message comprises of signals, cues and expressive signs [...] which play their role in receiving and sending the messages other than the medium of language". In addition to the components of NVC stated above, $\underline{\text { Calero }}$ $\underline{(2005)}$ add on some other elements namely, sense of touch, smell, hearing, signs, intuition, and symbols as the fraction of nonverbal messages we receive. Charles Darwin also contributed to the field of NVC.

In everyday lives, people are interacting in numerous ways. Most vital among them is of course employing language (verbal communication). In the selection of words, the intended idea must be precisely conveyed in the words of the speaker. It is very important to make use of the brief, clear, accurate, and rich expression in the oral communication for the transmission of the concepts or ideas properly to the listeners (Najafi, 2013). Verbal language is divided into four skills; writing, listening, speaking, and reading. Speaking skills are the most imperative amongst all these skills. They have the maximum degree of usefulness and prominence in the field of oral communication (Khabaz, 2013).

Chaudhry \& Arif researched in 2012 and they concluded that verbal language alone doesn't influence the learners' mind as much as the non-verbal does. This is because of the reason that NVC is always complementing verbal communication. Similar verbal message can be oppositely interpreted and perceived by the learners by the means of non-verbal elements (p. 57). Azaoui (2013) conducted a similar kind of study, his research offers the chance to add to our understanding of the influence of teachers' non-verbal pedagogical repertoire. Vivid and rich expression of gestures by the teacher stimulates the 
students to listen with interest and willingness (Barabar \& Caganaga, 2015). Mandal (2014) researched non-verbal communication and he concluded that nonverbal cues help provide feedback and meta-communication in the language class.

A successful educator in the field of language teaching must be aware of the power of non-verbal cues, which are used either consciously or unconsciously. Haneef, et al (2014) argued that most of the times NVC happens unconsciously. Most of the teachers are not aware of the fact that their non-verbal message is far stronger than the verbal one and it is leaving a significant impact on learners. The body language, movement of the eye, physical appearance, and the various aspects of voice convey a significant message to the listeners. NVC seems more influential and reliable as compared to verbal communication as it provides additional support to the verbal message (p. 513).

To this end, it is the requirement for the language instructors and trainers to gain the competence which can shape the communicative process more efficient to succeed in achieving the desired outcome from the students (Butt, 2011). Eunson (2012) says that the central skill is to master the art of using effective non-verbal language in the class along with verbal language.

\section{Non-verbal language in teaching English as L2}

Barabar and Caganaga (2015) stated that "nonverbal communication is the inevitable part of language teaching which assists in flourishing teaching quality and the progression of teaching methods, as well as aids teachers to obtain the students' attention easily". To attain communicative competence is one of the main intentions of language class, and nonverbal language comprises the indispensable part of the whole communicative act.

Galloway (1968) stated that "nonverbal communication is the cardinal characteristic of oral communication which is frequently overlooked and ignored by the instructors who are teaching English as a second language. Thus, it is requisite to research in the field of NVC'. Hong-li (2011) researched in China that how nonverbal actions of teachers influence the students and it was concluded that the importance of nonverbal language cannot be denied in the educational context. Students in the class observe the body language of their teachers and make judgments about the role and performance of teachers. Mehrabian (1971) stated that teachers who are more inclined to use appropriate nonverbal behavior in the class, cultivate further positive attitudes from the students. According to Eaves and Leathers (2017), the physical appearance of people influences our perception, how we view them as a person. In a class where English is taught as a second language, learners come with many barriers including anxiety and lack of interest therefore, the dull and tiresome appearance of language teachers can further demotivate them (Martens et al., 2009). A similar type of study was conducted by Malik (2021) he concluded that teachers in the language class can make their lectures interesting and fun by mixing the non-verbal aspect of the language, thus decreasing the language learning barriers and increasing the level of achievement of the language.

Moreover, Elfathi (2006) suggested that in an ESL classroom, teachers should use nonverbal language more consciously and effectively to make students relax, comfortable and to reduce language learning anxiety.

\section{METHODOLOGY}

This study is a twofold or mixed research because it makes use of the principles of both quantitative and qualitative approaches. Quantitative and qualitative methods i.e. close-ended questionnaires and interviews, both are used to acquire more reliable results. These techniques can have a two-fold benefit for the researcher. Firstly, the maximum number of data was collected in a short time period by using these techniques. Secondly, these techniques helped the researcher to control the unwanted variables. Thus, make the findings more valid and reliable.

\section{Data collection tools}

Data collection tools are the pillar of any survey study. It has been said that good research should use more than one tool to be more reliable and authentic. Therefore, both questionnaires and interviews are used in this study to gather the desired data.

\section{Questionnaire}

A questionnaire consisted of 37 close-ended questions are used in the present study. The questionnaire is comprised of five segments related to different elements of non-verbal communication. In the first section, there are ten questions, related to the facial expressions of the English teachers. Section two comprised six questions about the eye movement or eye contact of the teacher. Section three includes eight questions, in which students were inquired about the influence of the teacher's body movement in the class. Section four and five covers the questions related to another non-verbal aspect i.e. pitch of voice and spatial distance respectively. 
Table 1: Description of questionnaire's items

\begin{tabular}{llll}
\hline No. & Non-Verbal Constructs & Item No. & Total Questions \\
\hline 1. & Facial Expressions & $1.1,1.2,1.3,1.4,1.5,1.6,1.7,1.8,1.9,1.10$ & 10 \\
\hline 2. & Eye Contact & $2.1,2.2,2.3,2.4,2.5,2.6$ & 06 \\
\hline 3. & Body Movements & $3.1,3.2,3.3,3.4,3.5,3.6,3.7,3.8$ & 08 \\
\hline 4. & Tone of Voice & $4.1,4.2,4.3,4.4,4.5,4.6,4.7$ & 07 \\
\hline 5. & Spatial Distance & $5.1,5.2,5.3,5.4,5.5$ & 05 \\
\hline
\end{tabular}

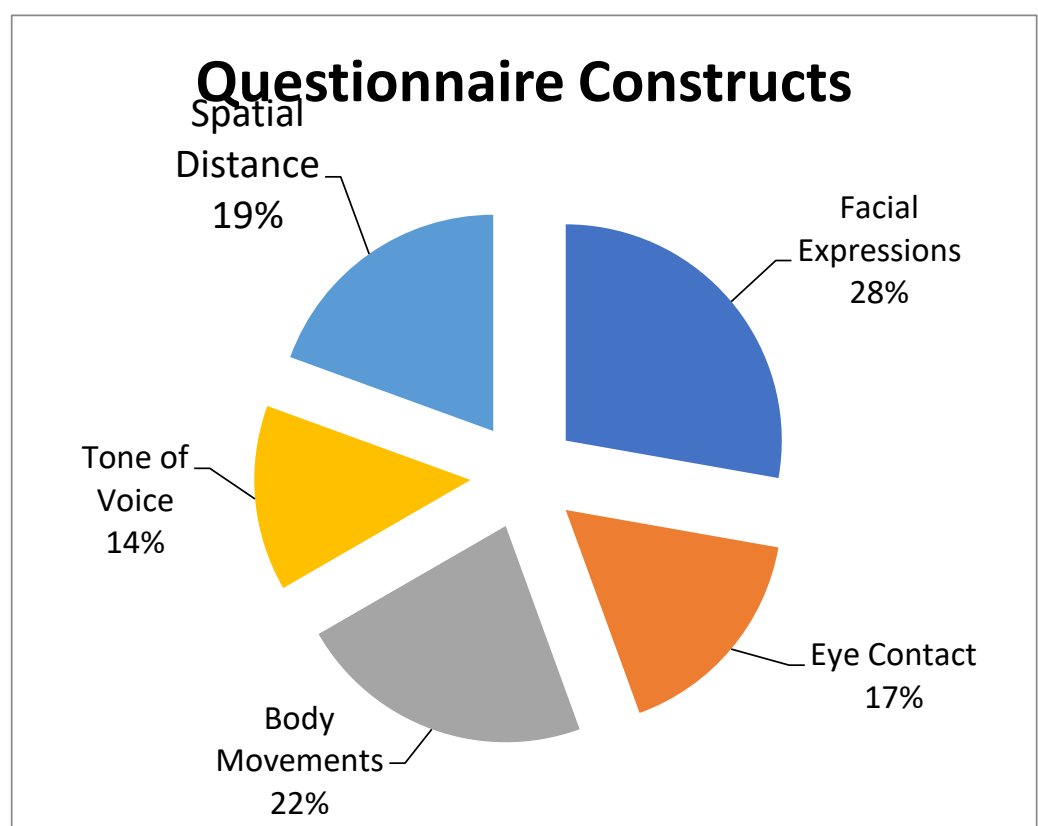

Figure 1: Percentage of the constructs of the questionnaire

\section{Interview}

A brief interview was conducted with ESL students about the use of NVC by their English teachers. Interviewees were requested to list some of the features of NVC used by their English teachers, the effectiveness of non-verbal cues, and the influence of NVC on the level of achievement of the English language.

\section{Population and sample}

This current research is conducted at The Islamia University of Bahawalpur. The target population of the study is ESL students. They were nominated to gather more reliable and creditable results because the researcher wanted to explore the influence of non-verbal cues used by the teachers in an ESL class. The sample of respondents comprises 100 students, 57\% of which are female students. The average age of the respondents ranges from 19-24 years. All these students are enrolled in the Islamia University of Bahawalpur at the graduate level.

\section{Data analysis}

The numeric data is gathered from the respondents through questionnaires. Collected data is analyzed to reveal the findings. Data is analyzed in SPSS version 21.0; calculating frequency, mean, and percentage. The significant variables in the demographic information are gender, age, and academic qualification. A mean response is calculated for each variable by adding all responses and dividing them by the total number of respondents. Histograms are constructed to present the findings systematically.

Furthermore, data that is collected through interviews are analyzed qualitatively. Content analysis of interviews is carried out. To analyze the discourses of the respondents, an Inductive approach is used. Interviews are brought in the written form and the certain repeated phrases and keywords are highlighted. These words/phrases are coded. Codes are narrowed down into 5-7 overarching codes. After coding final themes are selected. The ultimate themes reflect the drive of the research.

\section{RESULTS AND DISCUSSION}

\section{Analysis of Non-verbal constructs of the questionnaire}


i. Facial Expressions: Facial expression is the first non-verbal construct in the questionnaire. This part comprises the questions related to the impact of facial expressions of the English teachers. The majority of the respondents (92\%) agree that they perceive the expressions on the face of their English teacher and these expressions affect the learning process in the language class.

This category was included to investigate that to what extent expressions on the face of the teacher affects the learners in the ESL class. It reveals the consequences of the teacher's anger or smiles on the learners' achievement of language. The graph illustrates that the majority of students perceive facial expressions positively and they are more motivated by the expressions of the teacher rather than dull or plain face.

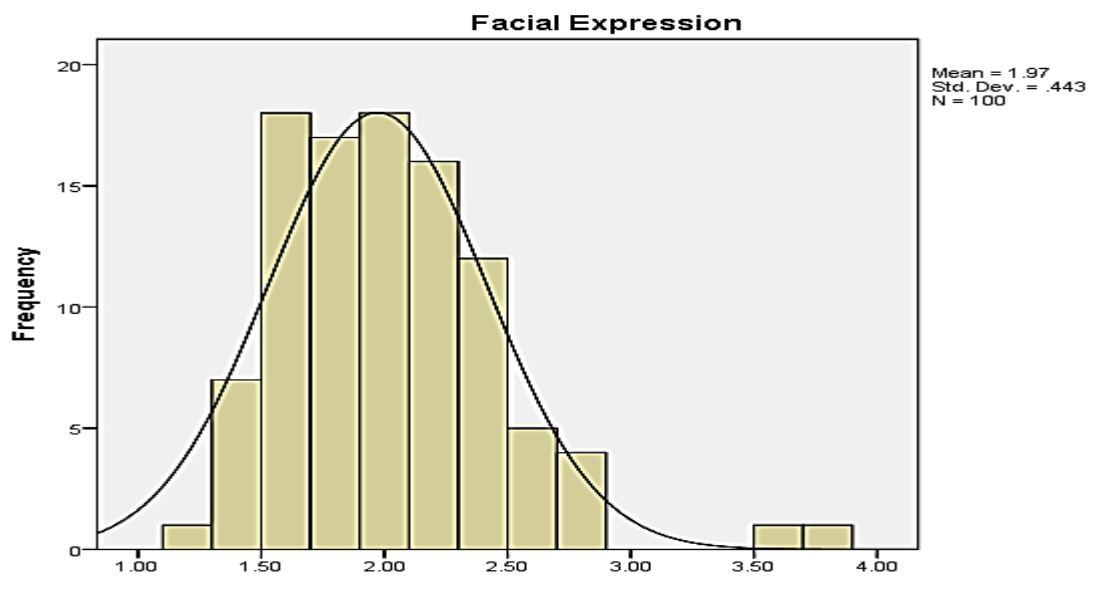

Figure 2: Standard deviation and mean value of the construct of Facial Expression

ii. Eye Contact: The second non-verbal construct is 'eye contact'. This section throws light on the influence of effective eye contact by the English teacher. $96.4 \%$ of respondents believe that eye contact in the language class makes them motivated and alert. They are more likely to grasp the concepts by looking into the eyes of the teacher. Therefore, eye contact with the teachers assists in better learning.

This variable is included in the questionnaire since eye contact is an important component of non-verbal behavior. This section aids in exploring the impact of eye contact in the language teaching environment, particularly where English is taught as a second language. The curve in the graph shows that learners take notice of the teacher's eye contact and they feel more attentive and concerned in the language/grammar lesson when the teacher makes regular eye contact with them.

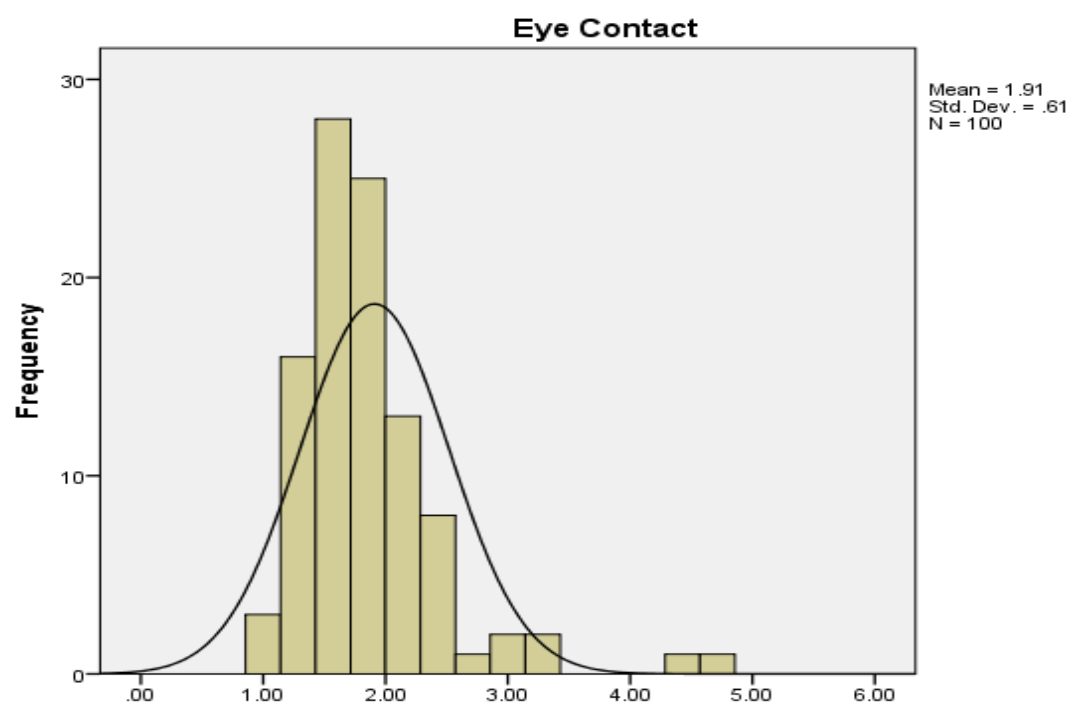

Figure 3: Standard deviation and mean value of the construct of Eye Contact

iii. Body Movements: The next non-verbal construct in the questionnaire is 'bodily movements'. This variable comprises of the several movements or body positions of the Language teacher including gestures and postures. Results reveal that about 
$83 \%$ of the students believe that they are influenced and affected by the gestures and postures of their language teachers. The majority of the respondents hold that they perceive the bodily movements of their teacher more consciously.

This section contains the questions related to the gestures or the movement of the teacher in the class. This component was incorporated due to the key role played by the bodily cues in NVC. Therefore, it is imperative to investigate that either student perceives the movement of the hands or body during the language class in a positive way or not. The curve in the graph illustrates that about $80 \%$ of students agree on the notion that bodily cues along with gestures make them attentive and focused in the class.

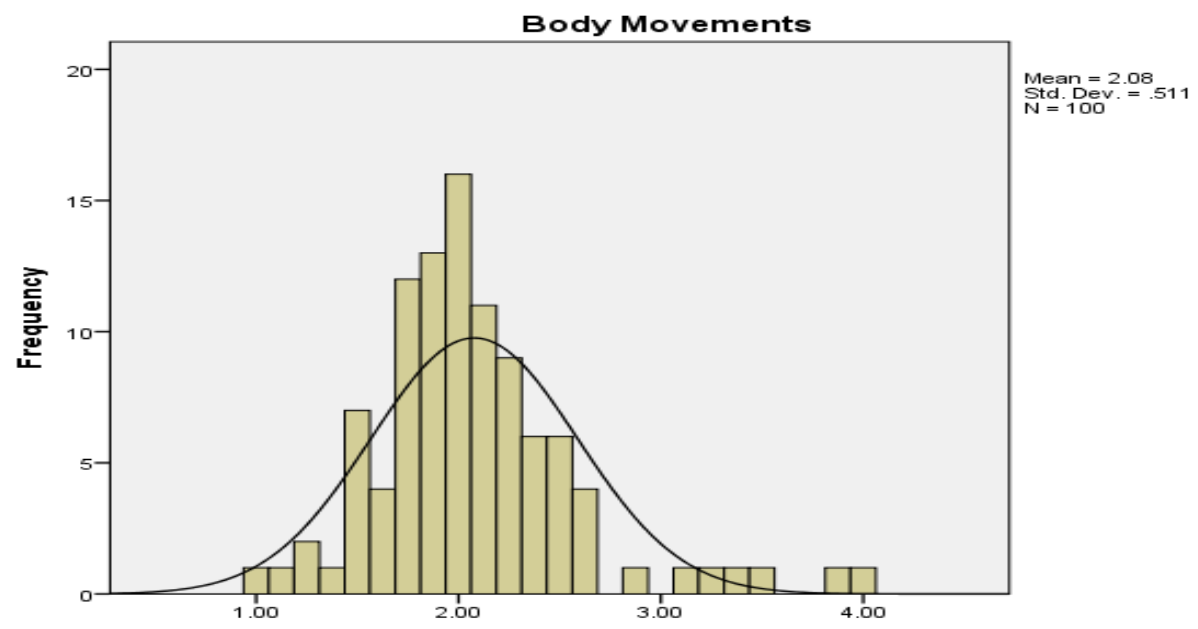

Figure 4: Standard deviation and mean value of the constructs of Body Movements

iv. Pitch of Voice: 'Pitch of the voice' is another dominant non-verbal cue. The fourth section of the questionnaire consists of the questions concerning the effect of the tone of voice, intonation, rate, and speed of speech of the English teachers. The mean value is 1.98 which specifies that the majority of the students perceive the variation in teachers' speech consciously. It proposes that learners are affected by the tone of voice of the teacher.

This section is included to investigate the effect of intonation, tone, or rate of speech of the English teacher on learners and their level of achievement of the language. However, this element of non-verbal language is frequently ignored by the teachers but results reveal that more students are strongly agreed that they adore the intonation in the teachers' speech.

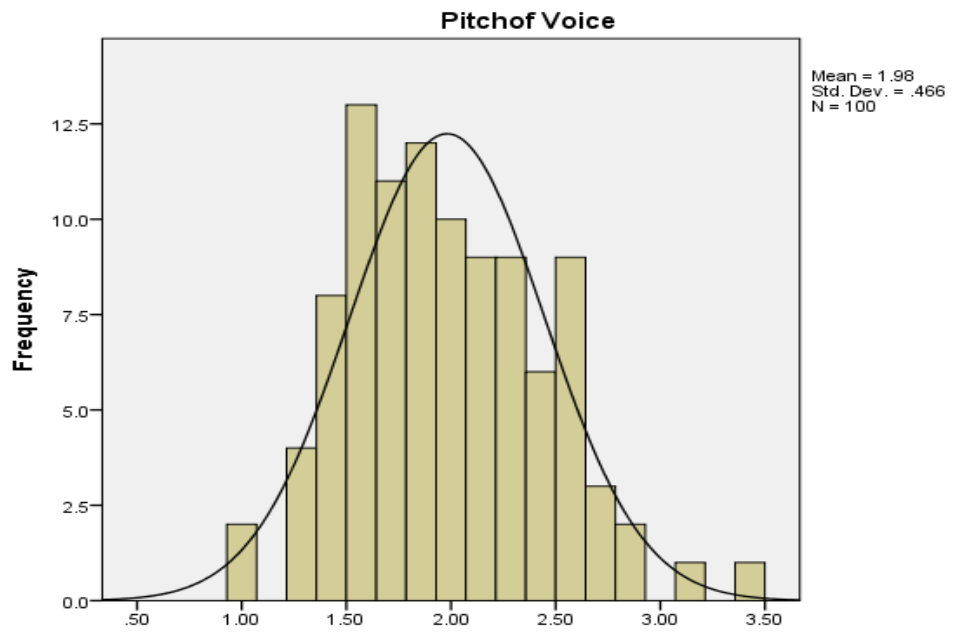

Figure 5: Standard deviation and mean value of the constructs of Pitch of Voice

v. Spatial Distance: The final construct in the questionnaire is 'spatial distance' or, 'proxemics'. This segment intends to investigate the impact of the use of proxemics appropriately in the ESL class. In this section respondents are questioned about their perception or notion of proxemics, whether they are more relaxed and attentive while sitting/standing 'near', 'not far' or 'far' from the teacher. The majority of the respondents chose 'not far'. The mean value is 2.30 which indicated that 
the majority of the participants choose to sit near or close to the teacher and they are convinced that it improves their learning in the language class.

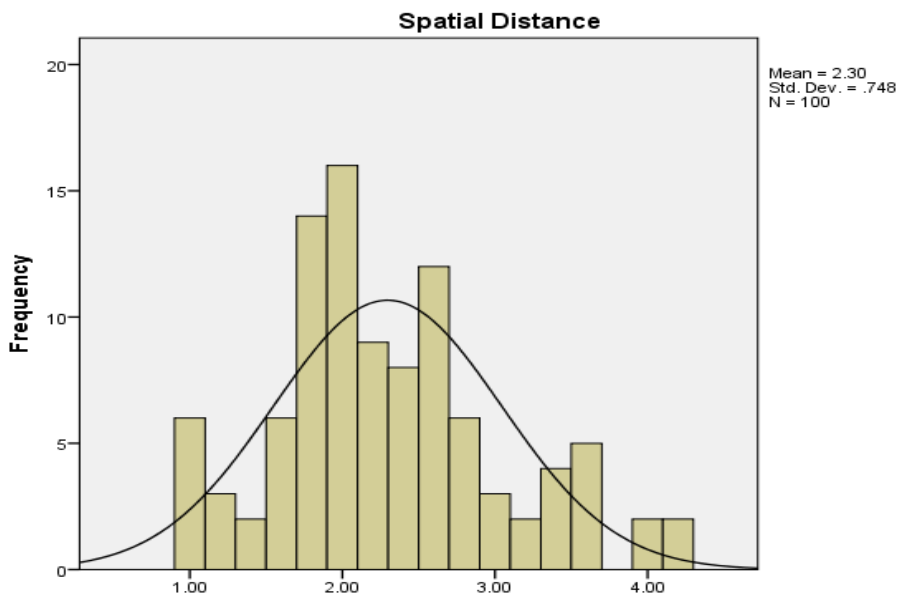

Figure 6: Standard deviation and mean value of the constructs of Spatial Distance

\section{Analysis and discussion of the responses collected through interviews}

After analyzing the questionnaires, the second step is to examine and discuss the interviews, taken from the respondents.

In the first place, participants are requested to put forward their understanding of nonverbal language. $52.273 \%$ of the participants explained non-verbal language as an exchange that encompasses various features of non-verbal communication. Respondents stated the following elements of non-verbal language: mime, gestures, eye contact, body position, motion, facial expressions, head nodding, hand movement, speech rate, intonation, tone, situational context (like behavior code, environment), the use of touch and space, the distance between the participants of the conversation, personal style, physical appearance of the person, clothing, negative or the positive vibes that the speaker holds. $27.273 \%$ said that non-verbal language is the absence of spoken words. More particularly, they explained non-verbal language as all that is unsaid, the type of communication that is not written or spoken, communicating without using words, communicating with others by using all the means excluding the linguistic ones. When the responses to the first question are analyzed, it has been noticed that respondents repeatedly emphasize some particular points while giving their definition of non-verbal language:

i. Out of the total interviewees, six said that the exchange of information, message, and meaning without using verbal language is included non-verbal communication.

ii. Four respondents stressed that most of the times non-verbal communication is unconscious, however, two are of the view that non-verbal communication can go both ways i.e. unconscious and conscious, though the conscious part of non-verbal communication is usually learned.

iii. One of the participants underlined that non-verbal language is indispensable to the communicative process.

iv. While two of the total participants emphasized that non-verbal language is widely used to express sentiments, thoughts, and feelings, i.e. that non-verbal language enables people to perceive the emotions, feelings, and attitudes of other people.

v. One of the participants said that non-verbal language has the intention of directing attention.

vi. One respondent highlighted that non-verbal language is an unwished way of expressing what we wish for i.e. nonverbal signs or language that reflects the inner feelings and thoughts of the people which they are consciously hiding from others.

vii. One respondent simply said that non-verbal language is the type of communication that is used during teaching.

After defining non-verbal language, the participants are asked to give their opinion about the conscious or unconscious perception of non-verbal cues, of their English teachers. $76.136 \%$ of the participants maintained the view that non-verbal signs are perceived unconsciously, whereas a lesser number of participants (only $12.5 \%$ ) believe that they are perceived consciously. Moreover, 5.68\% of participants said that they perceive non-verbal signs in both ways i.e. consciously as well as unconsciously. Few respondents stood out with their responses:

i. One interviewee responded that non-verbal cues of their teachers are perceived unconsciously as a great number of 
gestures are uncontrollable. Such as pupil dilation.

ii. One said that the non-verbal language of teachers is perceived unconsciously. However, non-verbal behavior can be learnt.

iii. Whereas, one respondent said that non-verbal language/cues are perceived unconsciously, but that they are scrutinized consciously by the listener.

In the next step, the interviewees are asked to describe that how the Non-verbal language of their English language teachers affects their language learning. The majority of the participants $(60 \%)$ think that they count on the non-verbal signs of the teacher in an ESL class when they are not able to understand something in class. $20 \%$ of respondents hold that during storytelling or in the lesson of the poems, the tone of the teacher makes the lesson more stimulating and interesting, whereas $7.955 \%$ of the respondents never pay attention.

When the participants are asked about conscious paying attention to non-verbal symbols of the language teachers during the teaching process, the outcomes are different. $38.636 \%$ of the participants hold the opinion that they rarely pay attention to non-verbal language. However, $34.091 \%$ of the respondents say that they frequently pay conscious attention to the nonverbal language of the English language teachers. $14.773 \%$ of the respondents are of the view that they very often pay conscious attention, whereas only six interviewees (i.e. 6.818\%) believe that they always pay attention consciously to the non-verbal behavior of the teacher in an ESL class. Only $2.273 \%$ of the respondents hold that they never or rarely pay conscious attention to the non-verbal language of the teachers during ESL class. Moreover, only three out of the total respondents stated that conscious attention is being paid to the non-verbal language/signs of the English language teachers if they are not concentrated if anything is unnatural, or in case the lecture is uninteresting. Non-verbal cues of the English language teachers to which the students pay maximum conscious attention during the class are eye contact (68.81\%), body movements (55.68\%), and physical appearance of the teacher (25\%). A less number of the students approximately $10.227 \%$ said that they also pay attention to the movement of hands and the same percentage notice facial expressions of their teachers. Just two students stated that they pay conscious attention to the tone, intonation, and movement of the teacher around the classroom.

The final part of the interview includes the percentages that how much conscious or unconscious attention is being paid to the various aspects of non-verbal language including facial expressions, eye contact, body movements, and physical appearance of the English teacher. As far as the physical appearance of the English teacher is concerned plenty of participants, almost $68.182 \%$ hold the opinion that they perceive and observe the physical appearance more consciously. $15.909 \%$ said that they do not consciously observe the physical appearance hence it is perceived unconsciously. Whereas, $15.9 \%$ of the respondents believe physical appearance is perceived equally consciously as well as unconsciously.

Furthermore, when participants are being asked about the facial expressions $59.091 \%$ of them said that they perceive and read the expressions on their teacher's face more consciously. On the other hand, $23.864 \%$ of the respondents hold the view that they rather perceive the facial expressions unconsciously. Whereas, $17.04 \%$ of the participants said that the expressions on the face of the English teachers are perceived in both ways sometimes consciously and sometimes unconsciously. Eye contact is the third non-verbal sign mentioned during the interview. $53.40 \%$ of the interviewees said that they notice it consciously whereas, $29.54 \%$ of the respondents assume that it is perceived unconsciously by them. $17.04 \%$ of respondents said that sometimes they consciously notice the eye contact of the English teachers and sometimes it goes unconsciously. Finally, students are asked about the body language of their English teachers. $86.59 \%$ of participants maintained the opinion that they perceive it consciously. $13.41 \%$ of the respondents said that the body language of the teacher is perceived unconsciously in the class.

\section{CONCLUSION}

In ESL class learners come from diverse backgrounds and experiences. Most of the time they are not successful in learning the second language because of certain barriers which hinder their ability to grasp the content being taught. Barriers may include lack of motivation, language learning anxiety, or sometimes ill-treatment by their teachers. Therefore, English Language teachers can productively use non-verbal language in the ESL class to teach the learners.

After analyzing the outcomes of the current study, the following conclusions are outlined:

1. The concept of NVC is extended to vast dimensions and it is almost impossible to explain it by just focusing on some components of it.

2. Learners consciously observe and understand the expressions of the teachers. Facial expressions of the English Language teachers positively affect the teaching-learning process. Appropriate expressions relieve their language learning anxiety and students feel more encouraged and motivated. 
3. Body movements of the teacher help the students in understanding and comprehending the concepts more positively and they further make the classroom environment energetic and conducive to learning. The findings indicate that students differentiate between the "effective" and "average" teachers as stated by Willet (1976), "effective teachers" practice more motions during the interaction with the students or signifying certain concepts.

4. Frequent eye contact with the teacher makes the students attentive and alert. Therefore, promotes learning in the classroom.

5. The physical appearance of the teachers has a dynamic impact on the students. Students make judgments about the competence of the teaching by their physical appearance.

\section{AUTHORS' CONTRIBUTION}

1. Dr. Tahira Asghar has conceived the idea, worked on developing the research methodology and research tool, data analysis, and interpretation of quantitative data. Dr. Tahira also reviewed and revised the article and finalized it.

2. Aisha Ilyas has written the introduction, worked on data collection and literature survey.

3. Dr. Iram Rubab also organized sources for literature review and worked on the interpretation of qualitative data.

\section{REFERENCES}

1. Andersen, P. A. (1998). Nonverbal Communication: Forms and Functions. McGraw-Hill Humanities/Social Sciences/Languages.

2. Azaoui, B. (2013, June). One Teacher, Two Instructional Contexts. Same Teaching Gestures? Tilburg gesture research meeting, Netherlands.

3. Barabar A, Aysenil \& Caganaga, Kivanc, Cagda. 2015. "Using Nonverbal- Communication in EFL Classes." Cypriot Journal of Educational Sciences Vol.10: pp. 136-147.

4. Bunglowala, A., \& Bunglowala, A. (2015). Non-verbal communication: An integral part of the teaching-learning process. International Journal of Research in Advent Technology, 1.

5. Burgoon, J. K., Guerrero, L. K., \& Floyd, K. (2016). Nonverbal communication. Routledge. https://doi.org/10.43 24/9781315663425

6. Butt N. 2011. Impact of Non-Verbal Communication on Students' Learning Outcomes. Faculty of Arts, Social Sciences \& Education. Sarhad University of Science and Information Technology, Peshawar - Pakistan: D.Phil.

7. Calero, H., Henry. 2005. The Power of Nonverbal Communication: How You Act Is More Important Than What You Say. Los Angeles: Silver Lake Publishing

8. Chaudhry, A., \& Arif, M. (2012). Teachers' Nonverbal Behavior and Its Impact on Student Achievement. International Education Studies, 5(4). https://doi.org/10.5539/ies.v5n4p56

9. Dockrell, J. E., Bakopoulou, I., Law, J., Spencer, S., \& Lindsay, G. (2012). Developing a communication supporting classroom observation tool. London: DfE.

10. Duke, R., Charles. (1974). Nonverbal Behavior and the Communication Process." College Composition and Communication, 25, 397-404. https://doi.org/10.2307/356963

11. Eaves, M. H., \& Leathers, D. (2017). Successful Nonverbal Communication: Principles and Applications (5th Edition). https://doi.org/10.4324/9781315542317

12. Elfatihi, M. (2005). The Role of Non-Verbal Communication in Beginners' EFL Classrooms. Dhar Elmahraz.

13. Eunson, B., (2012). Non-Verbal Communication. In book: C21: Communicating in the 21st Century, Edition: 3, Chapter: NVC: John Wiley \& Sons.

14. Galloway, C. \& Charles, M. (1968). Nonverbal Communication. Theory into Practice, 7, 172-175. https://doi.org/10.1080/00405846809542151

15. Givens, B., David. (2002). The Nonverbal Dictionary of Gestures, Signs \& Body Language Cues. Washington: Center for Nonverbal Studies Press.

16. Haneef, M., Faisal, M. A., Alvi, A. K., \& Zulfiqar, M. (2014). The role of non-verbal communication in teaching practice. Science International, vol. 26, no. 1, 2014. Gale Academic One File, Accessed 10 May 2021.

17. Khabaz, Z. The effect of nonverbal language on teaching [Internet]; Tehran: Hamshahri Newspaper; 2013 [cited 2013 April 12] Available from: http://hamshahrionline.ir/

18. Knapp, L., Mark. (1971). The Role of Nonverbal Communication in the Classroom. Theory into Practice, 10, $243-$ 249. https://doi.org/10.1080/00405847109542337

19. Kesevan, H. V., Madzlan, N. A., \& Hashim, H. (2020). Social Signalling as a Non Verbal Behaviour of Teachers in ESL Classroom Interaction. Universal Journal of Educational Research, 8(11), 5576-5580. https://doi.org/10.131 $\underline{89 / u j e r .2020 .081161}$ 
20. Malik, A. (2021). Nonverbal language: teachers' use and students' perception. Jurnal Penelitian, Pendidikan, dan Pembelajaran, 16(6).

21. Mandal, F. B. (2014). Nonverbal Communication in Humans. Journal of Human Behavior in the Social Environment, 24(4), 417-421. https://doi.org/10.1080/10911359.2013.831288

22. Martens, M., Duvivier, R. J., \& Dalen, J. V. (2009). Student views on the effective teaching of physical examination skills: a qualitative study. Medical Education, 43(2), 184-191. https://doi.org/10.1111/j.1365-2923.2008.03283.x

23. Mehrabian, A. (2008). Silent messages. Training Journal. Published.

24. Najafi, T., Rahmanzade, A. The relationship between communication skills and educational effectiveness of teachers of girls in Valiasr Technical College in Tehran. Journal of media studies. 2013;8(4): 193-206. Persian.

25. O' Connor, A., \& Shumate, M. (2018). A Multidimensional Network Approach to Strategic Communication. International Journal of Strategic Communication, 12(4), 399-146. https://doi.org/10.1080/1553118 $\underline{X .2018 .1452242}$

26. Hong-li, P. (2011). Effects of Non-verbal Communication on College English Classroom Teaching. US-China Foreign Language, 9, 505-516.

27. Pennycook, A. (1985). Actions Speak Louder Than Words: Paralanguage, Communication, and Education. TESOL Quarterly, 19, 259-282. https://doi.org/10.2307/3586829

28. Postman, N. (2006). Amusing Ourselves to Death: Public Discourse on the Age of Show Business. London: Penguin Books.

29. Smith, A., Howard. (1979). Nonverbal Communication in Teaching. Review of Educational Research, 49, 631-672. https://doi.org/10.3102/00346543049004631

30. Vrij, A., Hartwig, M., \& Granhag, P. A. (2019). Reading Lies: Nonverbal Communication and Deception. Annual Review of Psychology, 70, 295-317. https://doi.org/10.1146/annurev-psych-010418-103135

31. Woolfolk, E., Anita \& Brooks, M., Douglas. (1985). The Influence of Teachers' Nonverbal Behaviors on Students' Perceptions and Performance. The Elementary School Journal, 85, 513-528. https://doi.org/10.1086/461418

32. Zand, S., Baradaran, M. Najafi, R., Maleki, A., \& Mahdipour, A. (2020). Culture and Gender in Nonverbal Communication. 8, 123-130. 